\title{
Integrasi Nilai Anti Korupsi dalam Kurikulum Sekolah dengan Pendekatan Komisi Pemberantasan Korupsi
}

\section{The Integration of Anti Corruption Values in the Curriculum with the Corruption Eradication Commission Approach}

\author{
Andhika Wirabhakti \\ Sekolah Tinggi Agama Islam (STAI) Syamsul 'Ulum Gunungpuyuh \\ Sukabumi, Jawa Barat, Indonesia \\ Lautzeloo29@yahoo.com
}

\begin{abstract}
Abstrak
Strategi anti korupsi merupakan hal penting dalam membangun keberhasilan suatu lembaga kependidikan. Tujuan penelitian ini membahas integrasi nilai anti korupsi dalam kurikulum sekolah dengan pendekatan Komisi Pemberantasan Korupsi (KPK). Penelitian ini menggunakan penelitian kepustakaan yaitu itu dengan cara mengumpulkan data pustaka, atau penelitian yang obyek penelitiannya digali melalui beragam informasi kepustakaan (buku, ensiklopedi, jurnal ilmiah, koran, majalah, dan dokumen). Berdasarkan kajian ditemukan bahwa strategi anti korupsi dengan pendekatan Komisi Pemberantas Korupsi (KPK) dapat dilihat dari keberhasilan KPK dalam mencegah dan menindak tegas tanpa pandang bulu para koruptor yang ada di wilayah Negara di Indonesia. Adapun pengintegrasian nilai-nilai anti-korupsi dalam kurikulum sekolah diupayakan dengan menanamkan nilai-nilai anti korupsi di sekolah dengan beberapa alternatif model yang bisa digunakan yaitu model sebagai mata pelajaran tersendiri, model terintegrasi dalam semua mata pelajaran, model di luar pembelajaran, model pembudayaan dan pembiasaan nilai dalam seluruh aktivitas dan suasana sekolah dan terakhir model gabungan.

Kata kunci: Anti Korupsi, Komisi Pemberantasan Korupsi \& Kurikulum Sekolah
\end{abstract}

\begin{abstract}
Anti-corruption strategy is important in building the success of an educational institution. The purpose of this study discusses the integration of anti-corruption values in the school curriculum with the Corruption Eradication Commission (KPK) approach. This research uses library research that is by collecting library data, or research whose research objects are excavated through various library information (books, encyclopedias, scientific journals, newspapers, magazines, and documents). Based on the study it was found that the anti-corruption strategy with the Corruption Eradication Commission (KPK) approach can be seen from the
\end{abstract}


success of the KPK in preventing and cracking down indiscriminately on the corruptors in the territory of Indonesia. The integration of anti-corruption values in school curriculums is pursued by instilling anti-corruption values in schools with several alternative models that can be used, namely models as separate subjects, integrated models in all subjects, models outside of learning, models of culture and habituation of values in all school activities and atmosphere and finally the combined model.

Keywords: Anti-Corruption, Corruption Eradication Commission \& School Curriculum

\section{PENDAHULUAN}

Dalam Kamus Besar Bahasa Indonesia korupsi berarti busuk, palsu, suap. Pengertian korupsi dapat menjadi lebih luas lagi diantaranya seperti perbuatan seperti berbohong, menyontek di sekolah, mark up, memberi hadiah sebagai pelicin dan lain sebagainya. Dengan demikian, dapat diketahui bahwa tindakan korupsi merupakan sekumpulan kegiatan yang menyimpang dan dapat merugikan orang lain. Kasus-kasus korupsi seperti ini sangat banyak dijumpai dalam kehidupan sehari-hari dan cenderung sudah membudaya.

Jika diperhatikan, hampir disemua aspek kehidupan bangsa ini terlibat korupsi. Dari lembaga pendidikan sampai lembaga keagamaan sekalipun. Di lingkungan sekolah sangat banyak ditemui praktek-praktek korupsi, mulai dari yang paling sederhana seperti mencontek, berbohong, melanggar aturan sekolah, terlambat datang sampai pada menggelapkan uang sekolah pembangunan sekolah yang bernilai puluhan juta rupiah. Pada saat ini, ada indikasi terjadinya sikap apatis masyarakat terhadap tindakan korupsi. Masyarakat seakan telah jenuh dan terbiasa dengan kasus-kasus korupsi yang mencuat kepermukaan. Tidak ada sanksi moral dari masyarakat terhadap para koruptor. Bahkan secara tidak langsung budaya korupsi telah merajalela ditengahtengah kehidupan masyarakat.

Masyarakat harus mengetahui besarnya akibat yang ditimbulkan dari perbuatan korupsi tersebut, pendidikan menjadi mahal, begitu juga dengan pelayanan kesehatan, transportasi menjadi tidak aman, rusaknya infrastruktur dan yang paling berbahaya adalah meningkatnya 
angka pengangguran sehingga berkolerasi kepada angka kriminalitas. Pendirian Komisi Pemberantasan Korupsi (KPK) pada 29 Desember tahun 2002 merupakan sebuah itikad baik dari pemerintahan saat itu. KPK menjadi harapan baru bagi indonesia untuk mengobati penyakit bangsa yang sudah kronis.

KPK menjadi tumpuan harapan bagi bangsa ini untuk membongkar kasus korupsi dan memenjarakan para koruptor yang terlibat. Sampai saat ini KPK sudah menunjukan prestasi yang luar biasa. KPK membuat gebrakan dengan menjadikan beberapa gubernur sebagai tersangka. Disamping itu, KPK juga telah menjadikan beberapa Bupati sebagai tersangka kasus korupsi. Ditambah lagi dengan suksesnya KPK menggiring anggota Komisi Pemilihan Umum (KPU) Pusat, Mulyana Kusumah ke dalam penjara sebagai tersangka kasus suap melalui penyadapan telepon.

Mengingat begitu beratnya tugas KPK dan besarnya akibat yang disebabkan oleh kasus korupsi tersebut, maka diperlukan suatu sistem yang mampu menyadarkan semua elemen bangsa untuk sama-sama bergerak mengikis karang korupsi yang telah menggurita. Cara yang paling efektif adalah melalui media pendidikan. Diperlukan sebuah sistem pendidikan anti korupsi yang berisi tentang sosialisasi bentuk-bentuk korupsi, cara pencegahan dan pelaporan serta pengawasan terhadap tindak pidana korupsi. Pendidikan seperti ini harus ditanamkan secara terpadu mulai dari pendidikan dasar sampai perguruan tinggi.

Pendidikan anti korupsi ini sangat penting bagi perkembangan psikologis peserta didik. Pola pendidikan yang sistematik akan mampu membuat peserta didik mengenal lebih dini hal-hal yang berkenaan dengan korupsi temasuk sanksi yang akan diterima kalau melakukan korupsi. Dengan begitu, akan tercipta generasi yang sadar dan memahami bahaya korupsi, bentuk-bentuk korupsi dan tahu akan sanksi yang akan diterima jika melakukan korupsi. Sehingga, masyarakat akan mengawasi setiap tindak korupsi yang terjadi dan secara bersama memberikan sanksi moral bagi koruptor. Gerakan bersama anti korupsi ini akan memberikan 
tekanan bagi penegak hukum dan dukungan moral bagi KPK sehingga lebih bersemangat dalam menjalankan tugasnya.

Dengan adanya pendidikan anti korupsi, diharapkan akan lahir generasi tanpa korupsi sehingga dimasa yang akan datang akan tercipta Indonesia yang bebas dari korupsi. Harapan awal tentunya ini akan berdampak langsung pada lingkungan sekolah yaitu pada semua elemen pendidikan, seperti kepala sekolah, guru, karyawan dan siswa. Lingkungan sekolah akan menjadi pioneer bagi pemberantasan korupsi dan akan merembes ke semua aspek kehidupan bangsa demi mewujudkan Indonesia yang bebas dari korupsi.

\section{METODE PENELITIAN}

Jenis penelitian ini adalah penelitian kepustakaan (library research). Menurut Syaodih (2009) penelitian kepustakaan yaitu serangkaian penelitian yang berkenaan dengan metode pengumpulan data pustaka, atau penelitian yang obyek penelitiannya digali melalui beragam informasi kepustakaan (buku, ensiklopedi, jurnal ilmiah, Koran, majalah, dan dokumen). Menurut Farisi (2010) penelitian kepustakaan atau kajian literatur (literature review, literature research) merupakan penelitian yang mengkaji atau meninjau secara kritis pengetahuan, gagasan, atau temuan yang terdapat di dalam tubuh literatur berorientasi akademik (academic-oriented literature), serta merumuskan kontribusi teoritis dan metodologisnya untuk topik tertentu.

Tujuan penelitian kepustakaan atau studi literatur adalah untuk menemukan berbagai teori, hukum, dalil, prinsip, atau gagasan yang digunakan untuk menganalisis dan memecahkan pertanyaan penelitian yang dirumuskan. Adapun sifat dari penelitian ini adalah analisis deskriptif, yakni penguraian secara deskripstif data yang telah diperoleh, kemudian diberikan pemahaman dan penjelasan agar dapat dipahami dengan baik oleh pembaca. Hasil dari berbagai studi literatur ini akan digunakan untuk mengidentifikasi berbagai masalah tentang anti korupsi dalam manajemen sekolah bagi dunia pendidikan.

\section{HASIL DAN PEMBAHASAN}




\section{A. Pendekatan KPK (Komisi Pemberantasan Korupsi)}

Upaya pemberantasan korupsi yang dilakukan pemerintah Indonesia melalui pembentukan KPK (Komisi Pemberantasan Komisi) perlu diberikan apresiasi. Sejak berdirinya KPK pada tahun 2002 hingga sekarang, KPK telah menunjukkan hasil yang sangat baik. Menurut laporan KPK yang dimuat di laman http://kpk.go.id/id, Jakarta, 9 Januari 2017, sebagai bentuk pertanggungjawaban publik dan transparansi atas kinerja Komisi Pemberantasan Korupsi, disampaikan capaian dan kinerja KPK sepanjang tahun 2016 sebagai berikut:

KPK sebagai salah satu lembaga penegak hukum, berusaha senantiasa menjaga kinerja dalam hal pencegahan, penindakan maupun kelembagaan. Sejak lembaga ini berdiri, Laporan Keuangan KPK selalu memiliki Opini Wajar Tanpa Pengecualian (WTP). Demikian juga dengan Laporan Akuntabilitas Kinerja Instansi pemerintah (LAKIP), selama 6 (enam) tahun sejak tahun 2010, KPK memperoleh Nilai A. KPK juga meraih penghargaan peringkat pertama Keterbukaan Informasi Badan Publik Tahun 2016 kategori Lembaga Non Struktural (LNS) dari Komisi Informasi Pusat (KIP) (KPK, 2016). Terkait kapasitas kelembagaan, seluruh kegiatan KPK tahun 2016 dilakukan menggunakan anggaran yang berasal dari APBN, yaitu sebesar 991,8 miliar rupiah. Penyerapan anggaran pada tahun 2016 sebesar 843,9 miliar rupiah atau sekitar 85,09 persen.

KPK melakukan sejumlah terobosan dalam bidang teknologi, utamanya pada pendidikan dan peningkatan partisipasi publik dalam pemberantasan korupsi. Hal ini dilakukan dengan meluncurkan aplikasi platform JAGA, Gratifikasi Informasi dan Sosialisasi versi kedua, yakni GRATis $^{2} \mathrm{GO}$, dan pelaporan harta kekayaan berbasis elektronik melalui e-LHKPN. Inovasi tersebut didasarkan pada keyakinan bahwa kemajuan teknologi dapat dioptimalkan untuk pencegahan korupsi dengan melibatkan masyarakat sebagai aktor, karena mustahil bagi KPK dalam menjalankan tugas pemberantasan korupsi ini sendirian. 
KPK terus melaksanakan sosialisasi dan pendidikan antikorupsi guna meningkatkan partisipasi dan menjadikan masyarakat sebagai agen antikorupsi. Hal ini dilakukan melalui sejumlah program, misalnya dengan melibatkan para guru untuk membuat karya tulis antikorupsi melalui Teacher Super Camp; mencetak penyuluh antikorupsi melalui Master Camp; melibatkan pemuda dan anggota komunitas untuk melakukan perubahan di tengah masyarakat pada program Youth Camp; dan segmen mahasiswa dengan gelaran Festival Integritas Kampus; menyasar kaum perempuan melalui Gerakan Nasional Saya Perempuan Anti Korupsi (GN SPAK) dan yang tak terlupa, KPK juga menyasar segmen anak dengan mengadakan Festival Anak Jujur dan Teater Musikal Raksasa.

KPK juga menggunakan ragam cara, tak terkecuali caracara kreatif dalam menyebarkan pesan antikorupsi dan membangun karakter antikorupsi. Misalnya saja dengan menggelar Festival Lagu Suara Antikorupsi (SAKSI) yang diikuti dengan Konser Suara Antikorupsi dan pembuatan album para pemenang. Kegiatan ini diikuti oleh ratusan pemusik dari seluruh Indonesia dari beragam genre musik pada 3 regional, yakni Bandung, Yogyakarta dan Surabaya.

\section{B. Integrasi Anti Korupsi dalam Kurikulum Sekolah}

Kurikulum di sekolah merupakan penentu utama kegiatan sekolah. Berbagai kegiatan yang dilakukan di sekolah mulai dari dibukanya pintu sekolah sampai dengan lonceng pulang. Demikian juga dengan siswa yang mulai masuk sekolah, mereka melakukan kegiatan belajar berdasarkan kurikulum yang berlaku dan selalu disesuaikan dengan perkembangan ilmu pengetahuan dan teknologi yang berkembang. Kurikulum yang dirumuskan harus sesuai dengan filsafat dan cita-cita bangsa, perkembangan siswa, tuntutan, dan kemajuan masyarakat.

Undang-Undang Nomor 20 Tahun 2003 tentang Sistem Pendidikan Nasional menyatakan bahwa pendidikan nasional berfungsi mengembangkan kemampuan dan membentuk watak serta peradaban bangsa yang bermartabat dalam rangka mencerdaskan kehidupan bangsa, 
bertujuan untuk berkembangnya potensi peserta didik agar menjadi manusia yang beriman dan bertakwa kepada Tuhan Yang Maha Esa, berakhak mulia, sehat, berilmu, cakap, kreatif, mandiri, dan menjadi warga negara yang bemokratis serta bertanggung jawab.

Kurikulum adalah perangkat mata pelajaran yang diajarkan pada lembaga pendidikan, selain itu Kurikulum diartikan sebagai seperangkat rencana dan pengaturan mengenai tujuan, isi dan bahan pelajaran serta cara yang digunakan sebagai pedoman penyelenggaraan kegiatan pembelajaran untuk mencapai tujuan pendidikan tertentu.

Manajemen Kurikulum terkait dengan pendidikan anti dilakukan dengan cara: (1) Modifikasi isi/materi,

Modifikasi proses belajarmengajar, (3) Modifikasi lingkungan belajar, dan (4) Modifikasi pengelolaan kelas.

Masuknya pendidikan anti korupsi dalam sistem pembelajaran tidaklah harus dengan menambah mata pelajaran khusus tentang "PENDIDIKAN ANTI KORUPSI" tetapi lebih ditekankan pada internalisasi budaya anti korupsi memalui penyampaian materi ajar. Untuk kepentingan tersebut maka dibutuhkan modifikasi bahan ajar, proses pembelajaran, dan lingkungan belajar yang diarahkan pada penanaman budaya tersebut.

Sebagai contoh untuk mata pelajaran PKN adalah:

1. Materi Ketakwaan, untuk menanamkan keimanan dan takwa terhadap Tuhan Yang Maha Esa.

2. Materi Cinta Tanah Air, untuk menanamkan rasa memiliki, berani memiliki resiko, sikap tanggung jawab dan rela berkorban.

3. Materi Musyawarah, untuk menanamkan saling menghargai pendapat oranglain, memiliki jiwa sportif, dan kooperatif.

Ada beberapa model untuk menanamkan nilai-nilai anti korupsi yang dapat dipilih yang memiliki kelebihan dan kekurangannya sendiri-sendiri. Menurut Elwina dan Riyanto (2008) model-model tersebut antara lain:

1. Model sebagai mata pelajaran tersendiri

Pendidikan anti korupsi disampaikan sebagai mata pelajaran tersendiri seperti bidang studi yang lain. Dalam hal ini guru 
bidang studi pembelajaran anti korupsi harus membuat Garis Besar Pedoman Pengajaran (GBPP), Satuan pelajaran (SP), Rencana Pengajaran (RP), metodologi pengajaran, dan evaluasi pengajaran. Selain itu, pembelajaran anti korupsi sebagai mata pelajaran harus masuk dalam jadwal yang terstruktur.

2. Model terintegrasi dalam semua mata pelajaran

Penanaman nilai anti korupsi dalam pendidikan anti korupsi juga dapat disampaikan secara terintegrasi dalam semua mata pelajaran. Guru dapat memilih nilai-nilai yang akan ditanamkan melalui materi bahasan mata pelajarannya. Nilai-nilai anti korupsi dapat ditanamkan melalui beberapa pokok atau sub pokok bahasan yang berkaitan dengan nilai-nilai hidup. Dengan model seperti ini, semua guru adalah pengajar pembelajaran anti korupsi tanpa kecuali.

3. Model diluar pembelajaran

Penanaman nilai anti korupsi dapat ditanamkan melalui kegiatan-kegiatan di luar pembelajaran misalnya dalam kegiatan ekstrakurikuler atau kegiatan insidental. Penanaman nilai dengan model ini lebih mengutamakan pengolahan dan penanaman nilai melalui suatu kegiatan untuk dibahas dan dikupas nilai-nilai hidupnya. Model ini dapat dilaksanakan oleh guru sekolah yang bersangkutan yang mendapat tugas tersebut atau dipercayakan pada lembaga di luar sekolah untuk melaksanakannya, misalnya dari Komisi Pemberantasan Korupsi (KPK).

4. Model pembudayaan pembiasaan nilai dalam seluruh aktivitas dan suasana sekolah

Penanaman nilai-nilai anti korupsi dapat juga ditanamkan melalui pembudayaan dalam seluruh aktivitas dan suasana sekolah. Pembudayaan akan menimbulkan suatu pembiasaan. Untuk menumbuhkan budaya anti korupsi sekolah perlu merencanakan suatu kebudayaan dan kegiatan pembiasaan. Pembiasaan adalah alat pendidikan. Bagi anak yang masih kecil, pembiasaan sangat penting. Karena dengan pembiasaan itulah akhirnya suatu aktivitas akan menjadi milik anak di kemudian hari. Pembiasaan yang baik akan membentuk sosok manusia yang berkepribadian baik pula. Sebaliknya, pembiasaan yang buruk akan membentuk sosok 
manusia yang berkepribadian buruk pula (Djamarah,2002:72). Berdasarkan pembiasaan itulah anak terbiasa menurut dan taat kepada peraturan-peraturan yang berlaku di sekolah dan masyarakat, setelah mendapatkan pendidikan pembiasaan yang baik di sekolah pengaruhnya juga terbawa dalam kehidupan sehari-hari di rumah dan sampai dewasa nanti.

5. Model gabungan

Model gabungan berarti menggunakan gabungan antara model terintegrasi dan di luar pembelajaran secara bersamasama. Penanaman nilai lewat pengakaran formal terintegrasi bersama dengan kegiatan di luar pembelajaran. Model ini dapat dilaksanakan baik dalam kerja sama dengan tim oleh guru maupun dalam kerja sama dengan pihak luar sekolah. Keunggulan model ini adalah semua guru terlibat dan bahkan dapat dan harus belajar dari pihak luar untuk mengembangkan diri dan siswa. Anak mengenal nilai-nilai hidup untuk membentuk mereka baik secara informatif dan diperkuat dengan pengalaman melalui kegiatan-kegiatan yang terencana dengan baik. Dari penjelasan di atas dapat dibuat tabel seperti berikut:

Tabel I. Model Penanaman Nilai Anti Korupsi

\begin{tabular}{|c|l|l|}
\hline No & \multicolumn{1}{|c|}{ Model } & \multicolumn{1}{|c|}{ Keterangan } \\
\hline 1. & $\begin{array}{l}\text { Sebagai Mata Pelajaran } \\
\text { Tersendiri }\end{array}$ & $\begin{array}{l}\text { Pendidikan anti korupsi } \\
\text { disampaikan sebagai mata } \\
\text { pelajaran tersendiri seperti bidang } \\
\text { studi yang lain. }\end{array}$ \\
\hline 2. & $\begin{array}{l}\text { Terintegrasi dalam Semua Mata } \\
\text { Pelajaran }\end{array}$ & $\begin{array}{l}\text { Pendidikan anti korupsi } \\
\text { disampaikan secara terintegrasi } \\
\text { dalam semua mata pelajaran. }\end{array}$ \\
\hline 3. & Di Luar Pembelajaran & $\begin{array}{l}\text { Penanaman nilai anti korupsi } \\
\text { ditanamkan melalui kegiatan- } \\
\text { kegiatan di luar pembelajaran. }\end{array}$ \\
\hline 4. & $\begin{array}{l}\text { Pembudayaan pembiasaan nilai } \\
\text { dalam seluruh aktivitas dan } \\
\text { suasana sekolah }\end{array}$ & $\begin{array}{l}\text { Penanaman nilai-nilai anti korupsi } \\
\text { ditanamkan melalui pembudayaan } \\
\text { dalam seluruh aktivitas dan } \\
\text { suasana sekolah }\end{array}$ \\
\hline
\end{tabular}




\begin{tabular}{|c|l|l|}
\hline No & \multicolumn{1}{|c|}{ Model } & \multicolumn{1}{|c|}{ Keterangan } \\
\hline 5. & Gabungan & $\begin{array}{l}\text { Menggunakan gabungan antara } \\
\text { model terintegrasi dan di luar } \\
\text { pembelajaran secara bersama- } \\
\end{array}$ \\
& & \begin{tabular}{l} 
sama \\
\hline
\end{tabular} \\
\hline
\end{tabular}

Sumber: Elwina dan Riyanto (2008)

\section{KESIMPULAN}

\section{Pemikiran mengenai}

pendidikan berkarakter menjadi sangat penting di tengah upaya penyelenggaraan pendidikan antikorupsi. Kurikulum pendidikan anti-korupsi merupakan konsep yang ditawarkan untuk menanamkan nilai-nilai anti korupsi. Adapun beberapa model yang digunakan antara lain: (1) Model sebagai Mata Pelajaran
Tersendiri, (2) Model Terintegrasi dalam Semua Mata Pelajaran, (3) Model di Luar Pembelajaran, (4) Model pembudayaan, pembiasaan nilai dalam seluruh aktivitas dan suasana sekolah, (5) Model Gabungan. Lembaga KPK merupakan lembaga non struktural yang sangat penting untuk pencegahan dan penindakan terhadap perkara korupsi di Indonesia.

\section{DAFTAR PUSTAKA}

Abdurrohim. (2007). Analisis Wacana Pendidikan Anti Korupsi (http://stishidayatullah.ac.id. Diakses 21 Mei 2012).

Ahmad, Z. (2018). Strategi Anti Korupsi Melalui Pendekatan Pendidikan Formal dan KPK (Komisi Pemberantasan Korupsi): Journal Of Development and Social Change, 1 (2), 179-188.

Djamarah. (2002). Psikologi Belajar. Jakarta: Rineka Cipta.

Farisi, M. I. (2010). Pengembangan Asesmen Diri Siswa (Student SelfAssessment) sebagai Model Penilaian dan Pengembangan Karakter. Artikel disampaikan pada Konferensi Ilmiah Nasional "Asesmen dan Pembangunan Karakter Bangsa” HEPI UNESA 2012. 
Kamus Besar Bahasa Indonesia (2008). Jakarta: Gramedia Pustaka Utama.

KPK.( 2016). Capaian dan Kinerja KPK di Tahun 2016, di http://kpk.go.id/id/berita/siaran- pers/3832-capaian-dan-kinerja-kpkdi-tahun-2016 diakses 5-4-2018.

Laporan KPK Lamar http://kpk.go.id/id. Jakarta. 9 Januari 2017.

Rohiat. (2010). Manajemen Sekolah Teori Dasar Dan Praktik. Bandung: PT. Refika Aditama.

Sapon, S.(2018). Pendidikan Anti Korupsi. Pusat Pengembangan Dan Pemberdayaan Pendidik dan Tenaga Kependidikan Matematika. Yogyakarta.

Syaodih, N. (2009). Metode Penelitian Pendidikan. Bandung: PT. Remaja Rosdakarya.

Tim KPK. (2007). KPK Annual Report 2007. Jakarta: KPK

Tim KPK. Tanpa tahun. Pahami Dulu Baru Lawan Buku Panduan Kamu Buat Ngelawan Korupsi. Jakarta: KPK

Tim MCW. (2005). Seri Pendidikan Anti Korupsi Mengerti dan Melawan Korupsi. Jakarta: Kerjasama YAPPIKA dan MCW. 